\title{
Endovascular stent placement for pulmonary venous obstruction after Mustard operation for transposition of the great arteries
}

\author{
Jassim M Abdulhamed, Saad A Alyousef, Charles Mullins
}

\begin{abstract}
Stenting of the left pulmonary venous baffle obstruction was successfully performed in a 6 year old girl after the Mustard operation for transposition of the great arteries. She also had stent implantation in both the superior vena cava and inferior vena cava baffle junctions. These procedures were followed by sustained clinical improvement. Angiography showed that all three stents were fully patent a year after the procedure.
\end{abstract}

(Heart 1996;75:210-212)

Keywords: paediatric cardiac catheterisation; stents

Pulmonary venous obstruction is a well known complication after the Mustard operation..$^{1-3}$ It is usually treated by further surgery. ${ }^{4}$ This means another bypass operation on an already compromised right ventricle. The relief can be incomplete and obstruction can recur. ${ }^{4}$ Balloon dilatation of congenital and acquired pulmonary venous obstruction has been tried before with limited success. ${ }^{45}$

\section{Case report}

A 6 year old girl had a Mustard operation for transposition of the great arteries at the age of 9 months. When she was five and a half years old she presented with shortness of breath on moderate exercise with increasing blueness. Clinical examination revealed mild cyanosis with liver enlargement, the liver was $4.5 \mathrm{~cm}$ below the right costal margin at the midclavicular line. Cardiac catheterisation showed obstruction caused by the baffles in the inferior vena cava and superior vena cava. Balloon dilatation and stent implantation was successfully performed with a $3 \mathrm{~cm}, 3 \mathrm{~mm}$ PalmazSchatz stent (Johnson \& Johnson) in the inferior vena cava obstruction. This slightly improved the symptoms and reduced the size of the liver. Six months later she was catheterised and balloon dilatation with stent implantation in the superior vena cava was successfully performed. Both sides were dilated to $12 \mathrm{~mm}$.
A pulmonary artery angiogram was performed to visualise the pulmonary venous system. Because it suggested narrowing of the left pulmonary venous confluence we performed a detailed study of the pulmonary venous confluence.

A 7F transseptal sheath was manipulated through the right femoral vein to the systemic venous atrium. The sheath was pulled back slightly and the transseptal needle was directed anteriorly towards the pulmonary venous atrium, previously visualised during the levo phase of the pulmonary angiogram. The inferior wall of the baffle was punctured and the needle and dilator were removed. A $6 \mathrm{~F}$ NIH marker catheter was manipulated through the sheath to the pulmonary venous atrium and then to right and left pulmonary veins. Pressures and saturations were recorded and angiograms were performed on both sides. A $4 \mathrm{~mm} \mathrm{Hg}$ pressure gradient between the left upper pulmonary vein and the pulmonary venous atrium was recorded (table). Angiography showed moderate narrowing of the left pulmonary venous confluence (fig 1) which was $4 \mathrm{~mm}$ in diameter. The catheter was removed and $0.035 \mathrm{~mm}$ super stiff Meditech wire was advanced via the sheath to left upper pulmonary vein. An $11 \mathrm{~F}$ transseptal sheath was then manipulated over the wire to the left pulmonary vein. A $3 \mathrm{~cm}, 3 \mathrm{~mm}$ PalmazSchatz stent (Johnson \& Johnson) mounted over $12 \mathrm{~mm}, 3 \mathrm{~cm}$ long Meditech balloon over a $7 \mathrm{~F}$ shaft, was manipulated through the sheath and over the wire to the area of obstruction (fig 2). The sheath was pulled slightly, and an angiogram was performed to position the stent exactly. The balloon was inflated, expanding the stent to $12 \mathrm{~mm}$. The balloon was withdrawn and pressure measurements and angiography were repeated. The table shows pressure measurements before

Pressure measurements ( $\mathrm{mmHg}$ ) in the left upper pulmonary vein and pulmonary venous atrium before and after stent placement

\begin{tabular}{lll}
\hline & Before & After \\
\hline Left upper pulmonary vein & 14 & 10 \\
Pulmonary venous atrium & 10 & 10 \\
Gradient & 4 & 0 \\
\hline
\end{tabular}

\author{
Paediatric Ceparto \\ Riyadh Ardiac Centre, \\ Hospital, PO Box 7897 \\ Riyadh 11159, Saudi Arabia. \\ Accepted for publication \\ 30 August 1995 \\ Paediatric Cardiology, \\ Centre, Riyadh Armed \\ Riyadh, Saudi Arabia \\ J M Abdulhamed \\ C A Alyouse \\ Correspondence to
}




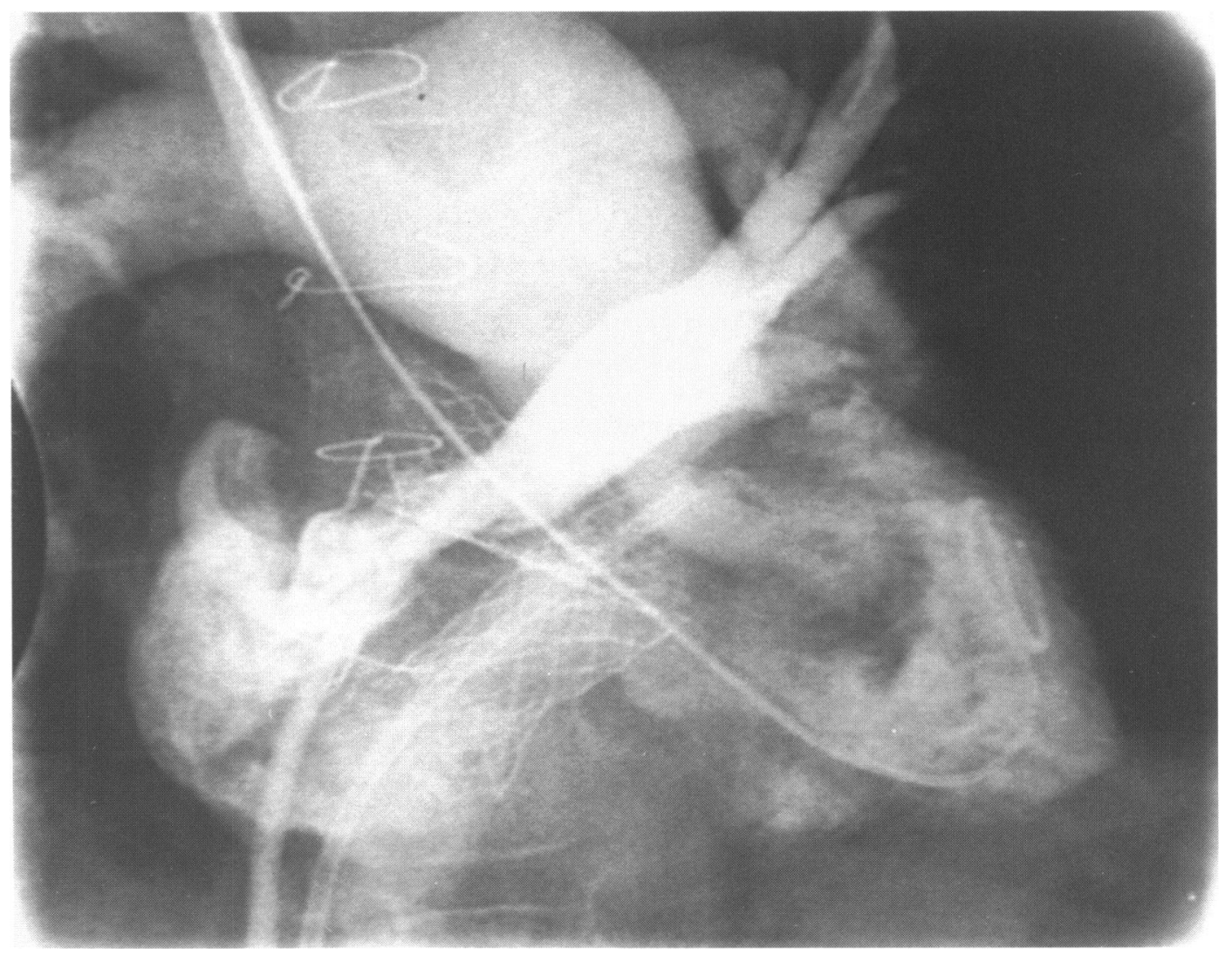

Figure 1 Angiogram (posterio-anterior) view of the left pulmonary venous confluence showing severe narrowing of the confluence. Note also the two stents at the junctions with the superior vena cava and inferior vena cava baffles.

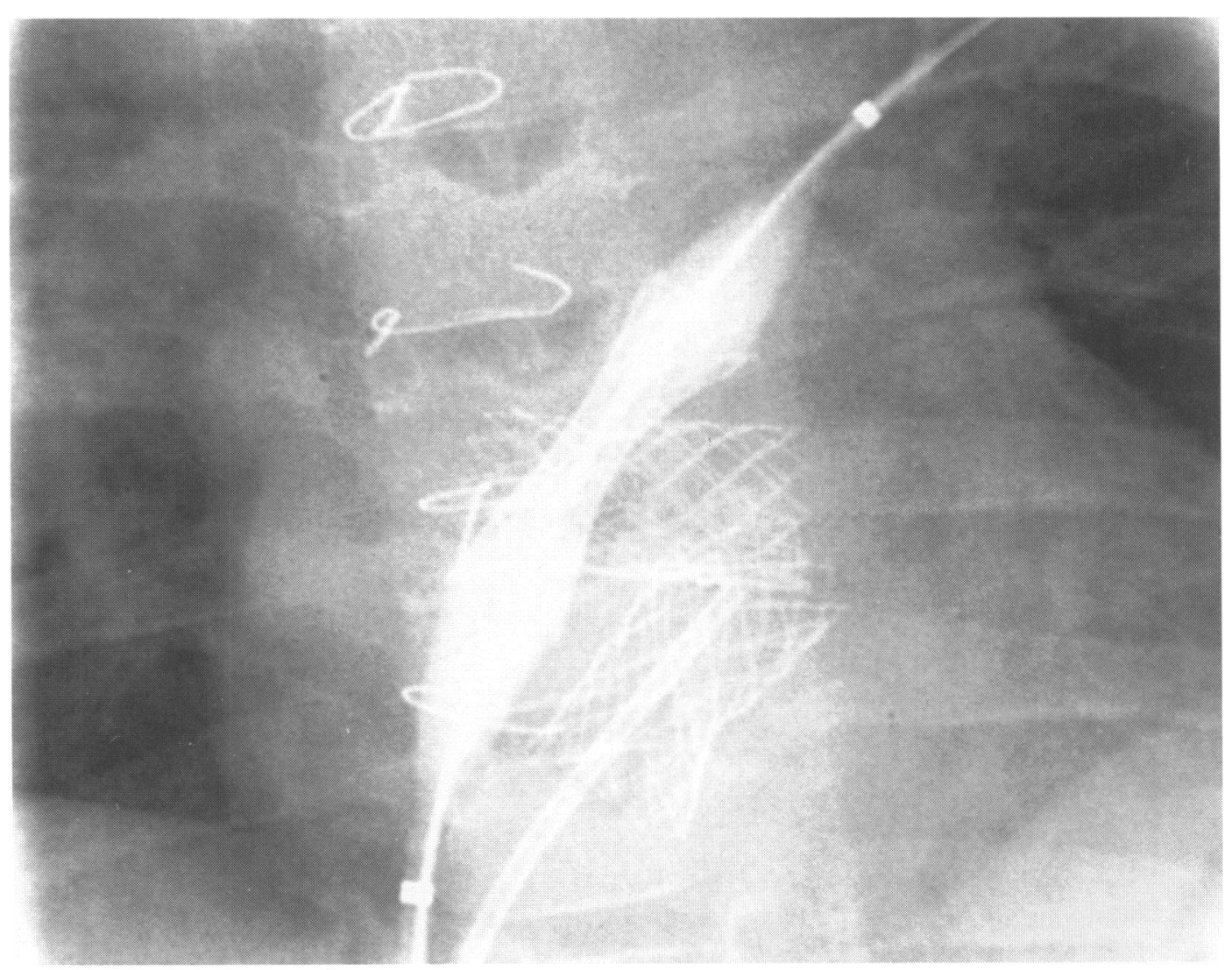

Figure 2 Posterio-anterior projection showing the stent partially inflated by a $12 \mathrm{~mm}$ ( $3 \mathrm{~cm}$ long) balloon inside the left pulmonary venous confluence.

and after stent implantation. The diameter of the stenosis was about $4 \mathrm{~mm}$. After stent implantation, the diameter increased to 12 $\mathrm{mm}$, thus giving a nine-fold increase in the area of stenosis.
The angiogram showed full patency of the left pulmonary venous confluence. The previous placed stents were not affected.

The patient was treated with a combination of dipyridamole and aspirin for 6 months. 
Figure 3 Left upper pulmonary vein angiogram (posterio-anterior projection) showing patency of the stent a year after implantation. The other two stents are also fully patent.

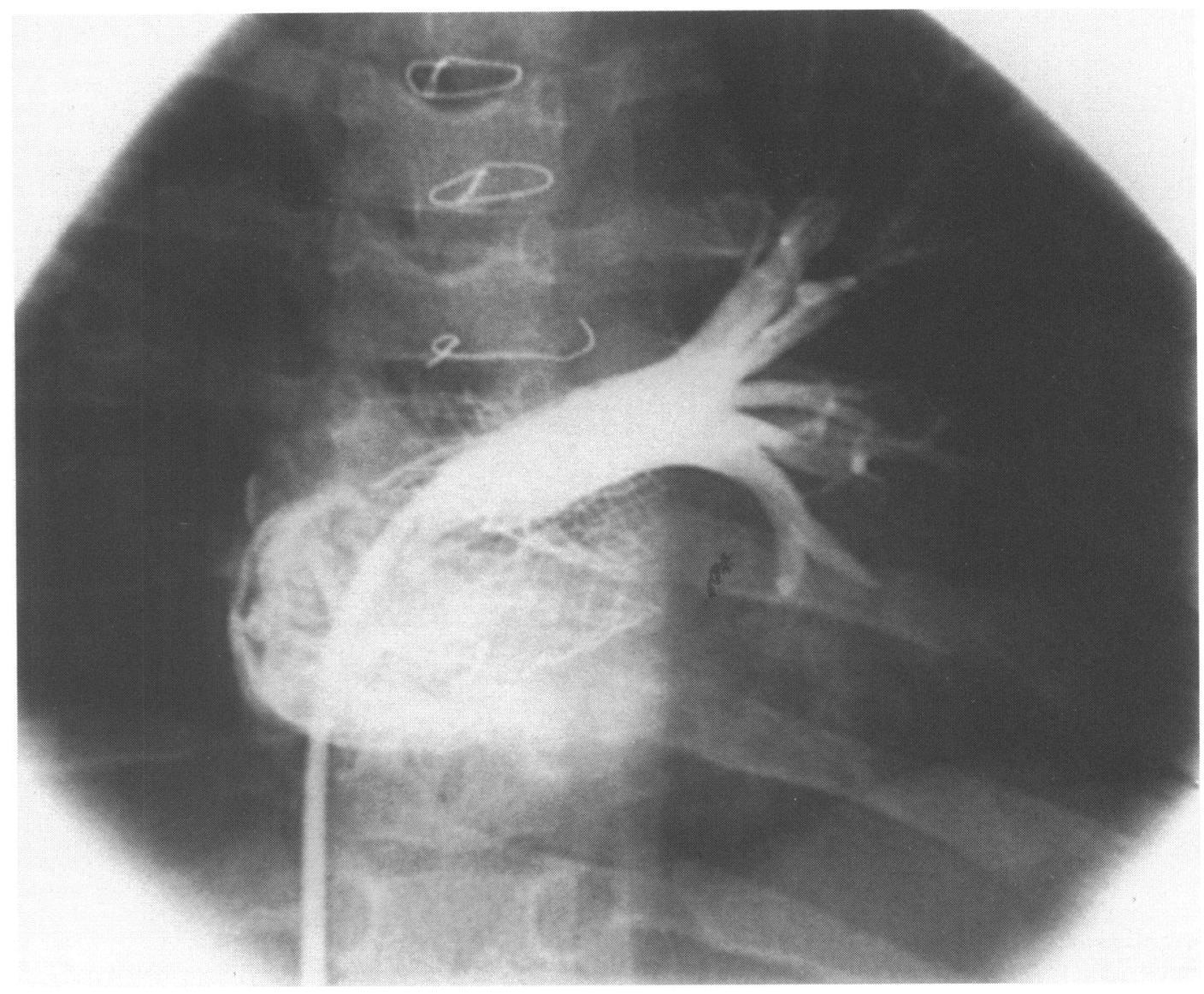

Cardiac catheterisation was repeated one year later and showed complete patency of the three stents (fig 3).

\section{Discussion}

This case illustrates the successful use of balloon expandable intravascular stent to treat acquired pulmonary venous obstruction after the Mustard operation. Although this stent implantation is technically difficult it is a promising treatment for a condition which is otherwise difficult to manage. It avoided further surgical repair and the associated risks of further bypass procedures.

We recommend the use of aspirin and dipyridamole, though the excellent patency of the stent a year later suggests that the risk of subsequent thrombosis or narrowing is low.
Implantation of stents may prove to be an effective treatment of pulmonary venous obstruction after the Mustard operation. ration of this paper.

1 Stark J, Tunan MJ, Ashcroft KW, Waterston DJ. Obstruction of pulmonary veins and superior vena cava after the tion of pulmonary veins and superior vena cava after the Mustard operation for transp

2 Eirculation 1972;45:116-20. $M$, Norwood WI, Castawda AR. Early and late results with the Mustard operation in AR. Early and late results with the Mustard

3 Trusler GA, Williams WG, Izukawa F, Olley PM. Current results with the Mustard operation in isolated transposition of the great arteries. $\mathcal{F}$ Thorac Cardiovasc Surg 1990; 80:381-9.

4 Cooper SG, Sullivan ID, Bull C, Taylor JFN. Balloon dilation of pulmonary venous pathway obstruction after Mustard repair for transposition of the great arteries. $\mathscr{F}$ Am Coll Cardiol 1989;14:194-8.

5 Lock JE, Bass JL, Castaneda-Zuni GAW, Guhrman BP, Rashkind WJ, Lucas RV. Dilation angioplasty of congenital or operative narrowings of venous channels. Circulation 1984;70:457-64.
We thank Lorne Thomson for her assistance during the prepa- 